\begin{tabular}{|c|c|c|} 
OmniAkuatika, $12(1): 48-54,2016$ \\
ISSN: 1858-3873 print / 2476-9347 online \\
Research Article
\end{tabular}

\title{
Valuasi Ekonomi Hutan Mangrove di Pulau Untung Jawa Kepulauan Seribu : Studi Konservasi Berbasis Green Economy
}

\author{
Dandy E. Prasetiyo ${ }^{1 *}$, Firman Zulfikar $^{2}$, Shinta ${ }^{3}$, Iskandar Zulkarnain ${ }^{3}$ \\ ${ }^{1}$ Program Studi Agribisnis, Fakultas Green Economy dan Digital Communication, Surya University \\ ${ }^{2}$ Program Studi Green Economy, Fakultas Green Economy dan Digital Communication, Surya University \\ ${ }^{3}$ Mahasiswa Program Studi Green Economy, Fakultas Green Economy dan Digital Communication, Surya \\ University
}

Corresponding author : dandy.prasetiyo@surya.ac.id

\begin{abstract}
Promoting forest as one of green economy asset in Indonesia become an important agenda in the process of development. Forests have an important role as a source of foreign exchange and also as a form of natural resource wealth. The era of globalization with the accelerated economic growth increases the need for both, the fields of agriculture, infrastructure, land requirements and other sectors. Increased human needs are giving a positive correlation to the increased pressure on forests. Mangrove forests as one of the most productive ecosystems in the world are also experiencing the same threat. The expansion of settlements and ponds in coastal areas lead to degradation of mangrove forests is very high. The economic value of mangrove forests of diverse functions such as shoreline protection, habitat for aquatic organisms, carbon storage, and a variety of other functions has not been a lot of concern to the public and policy makers. This study aimed to quantify the economic value of mangrove forests in Untung Jawa Island, Thousand Islands as an effort to support the government's program to realize the green economy in the forestry sector. Method of economic calculation mangrove forests in this research is to calculate the Total Economic Value / Total Economic Valuation (TEV), which consists of direct use values (Direct Use Value) and indirect use values (Indirect Use Value). The results showed that the direct use value of mangrove forests in Untung Jawa Island is Rp. 395,126,912 which includes the value of timber, fruit value, and the value of the fishery, while the indirect use value is $R p .7,500,600,000$ calculated from the value of coastal protection, the value of foraging, conservation value, educational value, and recreational value. The total economic value (total economic value) of mangrove forests in Untung Jawa Island reached Rp. $7,895,726,912$
\end{abstract}

Keywords : mangrove, green economy, total economic valuation

\section{Pendahuluan}

Hutan merupakan salah satu sumberdaya yang memiliki peran penting bagi kehidupan manusia (UNEP, 2014). Selain berperan sebagai penyangga kehidupan flora dan fauna dalam keseimbangan ekosistem, hutan juga merupakan bentuk kekayaan alam yang menjadi sumber devisa suatu negara. Memasuki era globalisasi, percepatan pertumbuhan ekonomi meningkatkan kebutuhan baik di bidang pertanian, infrastruktur, kebutuhan lahan, maupun sektor lain. Peningkatan kebutuhan tersebut menyebabkan tekanan terhadap hutan semakin tinggi. Hutan mangrove sebagai salah satu ekosistem hutan yang paling produktif di dunia juga mengalami tekanan yang sama.
Tindakan perluasan lahan permukiman dan tambak di wilayah pesisir menyebabkan degradasi hutan mangrove menjadi sangat tinggi mengingat mangrove memiliki tiga fungsi utama yaitu fungsi fisik (Prasetiyo, 2013) yang meliputi pencegah abrasi, perlindungan terhadap angin dan ombak, penyimpan cadangan karbon (Dharmawan dan Siregar, 2008) serta penghasil unsur hara (Hussain dan Badola, 2008). Fungsi biologis (Aksornkoae, 1993; Feller et al., 2006) yang meliputi tempat bertelur dan asuhan biota, tempat bersarang burung, maupun habitat biota laut lainnya, serta fungsi ekonomi (Prasetiyo, 2013) yang meliputi sumber kayu, hasil perikanan, pertanian, buah, bahan baku kertas, kulit dan obat-obatan (Zulkarnaini, 2012). 
Upaya mempromosikan hutan mangrove sebagai salah satu aset ekonomi hijau di Indonesia menjadi agenda penting dalam proses pembangunan saat ini. Ekonomi Hijau merupakan ekonomi yang menghasilkan peningkatan kesejahteraan manusia dan keadilan sosial namun mengurangi risiko lingkungan dan kelangkaan ekologis. Konsep Ekonomi Hijau muncul setelah adanya gejalagejala perubahan iklim yang menyebabkan kerusakan lingkungan di seluruh dunia akibat aktivitas ekonomi (UNEP, 2014). Salah satu penunjang utama untuk memenuhi kebutuhan ekonomi masyarakat Indonesia adalah sektor kehutanan, salah satunya adalah hutan mangrove.

Pulau untung Jawa merupakan salah satu destinasi wisata di Kepulauan Seribu yang menawarkan jenis wisata air dan hutan mangrove. Pulau Untung Jawa memiliki luas daratan mencapai 40,1 ha dengan luasan potensi mangrove sebesar 3,1 ha. Jenis mangrove yang ditemukan di Pulau Untung Jawa yaitu Rhizopora mucronata dan Avicenia alba (Bappedalda DKI Jakarta, 2000 dalam Santoso, 2005). Masyarakat banyak memanfaatkan mangrove di Pulau Untung Jawa sebagai tempat pemijahan ikan, penahan angin dan penahan ombak. Selama ini masyarakat Pulau Untung Jawa masih memiliki kesadaran yang tinggi untuk tidak merusak mangrove, tetapi meningkatnya aktivitas pariwisata dan pertambahan jumlah penduduk, tidak menutup kemungkinan masyarakat akan melakukan perluasan lahan dengan membuka lahan baru di kawasan hutan mangrove. Untuk mengantisipasi kondisi tersebut perlu dilakukan penyadaran secara terus menerus kepada masyarakat tentang fungsi dan potensi hutan mangrove, salah satu upaya yang dilakukan adalah dengan melakukan perhitungan valuasi total ekonomi sebagai salah satu konsep dari ekonomi hijau. Perhitungan valuasi ditujukan untuk memberikan gambaran total nilai ekonomi yang menjadi acuan dalam pemanfaatan hutan mangrove yang lestari sebagai upaya konservasi hutan mangrove.

\section{Metode Penelitian}

\subsection{Waktu, lokasi penelitian dan pengumpulan data}

Penelitian ini mengambil lokasi di kawasan hutan mangrove Pulau Untung Jawa, Kepulauan Seribu.Penelitian dilaksanakan pada bulan Februari 2015. Data yang diperlukan meliputi data primer dan data sekunder. Data primer merupakan data yang langsung diambil di lapangan atau lokasi penelitian. Dalam hal ini peneliti mengambil data mengenai mangrove melalui penelitian lapangan dan data yang dikumpulkan dari masyarakat diperoleh dari wawancara dan observasi. Responden untuk penelitian ini adalah masyarakat Pulau Untung Jawa yang memiliki aktivitas sehari-hari berhubungan dengan hutan mangrove baik secara langsung maupun tidak langsung (petani bibit mangrove, pengrajin, pencari ikan, nelayan) dan Stakeholder terkait dengan jumlah responden sebanyak 39 orang. Data sekunder diperoleh dengan cara mengumpulkan data pendukung dari berbagai instansi terkait di pemerintahan Pulau Untung Jawa. Data sekunder ini berupa data keadaan demografi, geografi dan kondisi sosial masyarakat Pulau Untung Jawa.

\subsection{Tehnik sampling}

Metode pengambilan sampel vegetasi mangrove dilakukan dengan Simple Random Sampling. Dalam pengambilan data vegetasi digunakan sistem transek dan kuadran. Transek (line transect) ditarik dari arah laut menuju ke darat dan ditempatkan kuadran dengan urkuran $10 \times 10 \mathrm{~m}$. Hal ini karena dalam penelitian ini mangrove yang diukur hanya pada kategori pohon.Sedangkan untuk metode pengambilan sampel responden menggunakan metode Accidental Sampling atau Convenience sampling yaitu teknik pengambilan sampel data atau responden yang jumlahnya tidak ditetapkan terlebih dahulu. Peneliti langsung mengumpulkan data dari unit sampling yang ditemui pada saat di lokasi penelitian (Kumaat, 2015). Masyarakat yang dijadikan responden adalah masyarakat yang memiliki aktivitas harian berhubungan langsung maupun tidak langsung dengan hutan mangrove. Responden diambil sebanyak 39 orang. Wawancara juga dilakukan kepada stakeholder di lokasi penelitian untuk mengetahui kebijakan yang di terapkan untuk kawasan mangrove dan keadaan umum lokasi penelitian.

\subsection{Metode pengolahan dan analisis data}

\subsubsection{Identifikasi manfaat dan fungsi-fungsi sumberdaya hutan mangrove}

Nilai ekonomi dalam sumberdaya hutan mangrove terbagi menjadi nilai penggunaan dan nilai non penggunaan. Penelitian ini hanya menggunakan nilai penggunaan, yaitu nilai langsung dan nilai tidak langsung.

nilai manfaat langsung (direct use value) 
Nilai manfaat langsung adalah nilai yang dihasilkan dari pemanfaatan secara langsung dari suatu sumberdaya. Manfaat langsung dapat diartikan sebagai manfaat yang dapat dikonsumsi. Nilai manfaat langsung dihitung dengan persamaan:

Dimana:

$$
\text { DUV }=\sum \text { DUVi }
$$

DUV = Direct Use Value

DUV 1 = Manfaat kayu

DUV 2 = Manfaat ikan

DUV 3 = Manfaat buah

nilai manfaat tidak langsung (indirect use value)

Manfaat tidak langsung adalah nilai dari sumberdaya mangrove yang dimanfaatkan secara tidak langsung oleh masyarakat. Manfaat tidak langsung hutan mangrove dapat dilihat dengan persamaan berikut:

Dimana:

$$
\text { IUV }=\sum I U V
$$

$$
\begin{array}{ll}
\text { IUV } & =\text { Indirect Use Value } \\
\text { IUV } 1 & =\text { nilai mangrove sebagai penahan } \\
\text { abrasi } & \\
\text { IUV } 2 & =\text { tempat mencari makan } \\
\text { IUV } 3 & =\text { rekreasi } \\
\text { IUV } 4 & =\text { edukasi } \\
\text { IUV } 5 & =\text { konservasi }
\end{array}
$$

\subsection{2. kuantifikasi manfaat ke dalam nilai uang}

Setelah seluruh manfaat dari hutang mangrove diidentifikasi, selanjutnya adalah mengkuantifikasi seluruh manfaat kedalam nilai uang dengan beberapa nilai yaitu:

a. Nilai pasar

Pendekatan nilai pasar ini untuk mengestimasi nilai ekonomi dari komoditas yang dimanfaatkan oleh masyarakat dari sumberdaya mangrove.

b. Harga tidak langsung

Pendekatan harga tidak langsung ini untuk mengestimasi nilai dari manfaat tidak langsung dari hutan mangrove.

c. Contingent Value Method (CVM)

Pendekatan CVM digunakan untuk mengestimasi nilai yang tidak dijual dipasaran, yakni nilai harga bibit dari petani.

\subsubsection{Nilai Total Ekonomi (Total Economic Value) \\ Pendekatan Total Economic Value
hutan mangrove merupakan}

penjumlahan total keseluruhan nilai ekonomi dari manfaat langsung dan tidak langsung dari hutan mangrove. Nilai Total Economic Value (TEV) menggunakan persamaan:

$$
T E V=D U V+I U V
$$

$$
\begin{aligned}
& \text { Dimana: } \\
& \text { TEV = Total Economic Value } \\
& \text { DUV = Direct Use Value } \\
& \text { IUV = Indirect Use Value }
\end{aligned}
$$

\section{Hasil dan Pembahasan}

\subsection{Kondisi pulau Untung Jawa}

Secara geografis, Pulau Untung Jawa terletak pada $106^{\circ} 39^{\prime} 30^{\prime \prime}$ - $106^{\circ} 57^{\prime} 40^{\prime \prime}$ BT $05^{\circ} 39^{\prime} 30^{\prime \prime}-05^{\circ} 54^{\prime} 26^{\prime \prime}$ LS. Luas wilayah Pulau Untung Jawa adalah 40,1 ha yang sebagian besar difungsikan sebagai wilayah permukiman. Sebagai tempat permukiman, sarana dan prasarana di wilayah ini cukup memadai, seperti MCK, tempat pembuangan akhir, jalur pedestrian, pengolahan air bersih dengan Reverse Osmosis (RO), listrik, serta alat transportasi darat dan laut. Seluruh fasilitas yang ada di Pulau Untung Jawa dapat dinikmati oleh masyarakat sekitar dan mampu mendorong masyarakat di luar Pulau Untung Jawa untuk melakukan wisata ke tempat ini. Daya tarik wisata Pulau Untung Jawa antara lain pantai dengan pasir putih yang dapat dipakai untuk berbagai kegiatan, seperti memancing, berenang, bersepeda, maupun watersport. Selain pantai, Pulau Untung Jawa juga memiliki Hutan Mangrove sebagai tempat wisata. Potensi mangrove di pulau ini sebesar 3,1 ha. Berdasarkan penelitian, jenis mangrove yang ada di Pulau Untung Jawa adalah Rhizopora Mucronata dan Avicennia alba dimana $R$. Mucronata menjadi jenis mangrove yang mendominasi kawasan ini.

\subsection{Nilai ekonomi mangrove}

Nilai guna langsung (direct use value)

Manfaat langsung hutan mangrove di Pulau Untung Jawa diperoleh dari estimasi pemanfaatan kayu mangrove, buah mangrove dan hasil penangkapan ikan yang diperoleh di kawasan hutan mangrove. Saat ini nilai pemanfaatan kayu mangrove oleh masyarakat hampir tidak pernah lagi dilakukan, hal ini terjadi karena kurangnya kesadaran masyarakat Pulau Untung Jawa akan pentingnya fungsi mangrove untuk keberlangsungan ekosistem pantai. Perhitungan nilai pemanfaatan kayu mangrove 
tetap dilakukan agar masyarakat dapat membandingkan nilai pemanfaatan kayu yang ditebang (destruktif) dengan pemanfaatan kayu sebagai komponen ekosistem dalam upaya perlindungan kawasan pantai.

Tabel 1. Hasil Perhitungan Nilai Manfaat Langsung Hutan Mangrove

\begin{tabular}{lcc}
\hline Manfaat Langsung & Nilai Pemanfaatan & Persentase \\
\hline Kayu & & \\
Buah & Rp. 268.551 .912 & $67,96 \%$ \\
Ikan & Rp. 45.000 .000 & $20,65 \%$ \\
\hline Total & Rp. 81.575 .000 & $11.39 \%$ \\
\hline
\end{tabular}

Tabel 1. menunjukan bahwa presentasi terbesar dari jenis manfaat langsung hutan mangrove di Pulau Untung Jawa adalah dari aktivitas pemanfaatan kayu mangrove sebesar $67,96 \%$. Kayu dari pohon mangrove dimanfaatkan sebagai kayu bakar dan sebagai bahan bangunan rumah masyarakat. Kemudian diikuti oleh pemanfaatan buah mangrove sebesar 20,65\%. Masyarakat Pulau Untung Jawa belum melakukan pengolahan pada buah mangrove dan mengonsumsinya secara langsung, serta pemanfaatan kawasan mangrove sebagai lokasi penangkapan ikan sebesar $11,39 \%$ dimana ikan yang ditangkap dan dikonsusmi oleh masyarakat Pulau Untung Jawa terdiri dari ikan gabus, ikan cenang, ikan bandeng, dan ikan mujair. Data tersebut memberikan gambaran bahwa nilai ekonomi kayu mangrove memiliki nilai ekonomi yang tertinggi. Oleh karena itu, upaya perlindungan tegakan mangrove menjadi sangat penting dilakukan di semua kawasan hutan mangrove, salah satunya di Pulau Untung Jawa. Perhitungan nilai pemanfaatan kayu mangrove, buah mangrove dan penangkapan ikan dilakukan dengan metode pendekatan harga pasar.

Nilai guna tak langsung (indirect use value)

Manfaat tidak langsung dari hutan mangrove di Pulau Untung Jawa terdiri atas manfaat fisik dan biologis. Nilai manfaat tidak langsung diolah menggunakan metode replacement cost (biaya pengganti), dimana perhitungan ini dilakukan dengan cara menghitung biaya yang akan dikeluarkan untuk menggantikan fungsi dari mangrove jika hutan mangrove ini dihilangkan. Berdasarkan hasil wawancara langsung, fungsi mangrove yang dirasakan masyarakat saat ini adalah hutan mangrove sebagai penahan abrasi atau gelombang air laut. Nilai manfaat hutan mangrove sebagai peredam gelombang laut yang diestimasi melalui pendekatan pembuatan breakwater. Manfaat tidak langsung lainnya yang dihitung antara lain mangrove sebagai tampat mencari makan ikan, nilai konservasi, nilai edukasi dan nilai pariwisata.

Tabel 2. Hasil Perhitungan Nilai Manfaat Tidak Langsung Hutan Mangrove

\begin{tabular}{|c|c|c|}
\hline Manfaat Tidak Langsung & Nilai Penerimaan & Persentase \\
\hline Penahan Abrasi & Rp. 7.478.800.000 & $99,71 \%$ \\
\hline Tempat Mencari Makan & 600.000 & $0,01 \%$ \\
\hline Nilai Konservasi & 5.000 .000 & $0,07 \%$ \\
\hline Nilai Edukasi & 7.200 .000 & $0,1 \%$ \\
\hline Pariwisata & 9.000 .000 & $0,12 \%$ \\
\hline Total & Rp. 7.500.600.000 & $100 \%$ \\
\hline
\end{tabular}


Manfaat tidak langsung mangrove sebagai penahan abrasi memiliki persentase tertinggi dibandingkan dengan komponen lainnya yaitu sebesar $99,71 \%$. Hal ini mengingat proses pembangunan breakwater yang memerlukan biaya sangat tinggi. Nilai tersebut diestimasi dari biaya pembangunan breakwater dan penahan gelombang air laut. Pembangunan breakwater untuk jarak $1 \mathrm{~m}$ memerlukan biaya sebesar Rp. 6.000.000. Apabila panjang garis pantai Pulau Untung Jawa yang terlindungi mangrove 1256,82 m, maka hasil yang diperoleh untuk manfaat mangrove sebagai penahan abrasi dan gelombang air laut adalah sebesar $\mathrm{Rp}$. 7.478.800.000. Nilai manfaat tidak langsung lainnya seperti tempat mencari makan, nilai konservasi, nilai edukasi dan nilai pariwisata diestimasi dengan metode pendekatan harga pasar dan willingness to pay oleh masyarakat. Metode pendekatan harga pasar berarti melakukan perhitungan dengan merumuskan harga jual yang ada di pasar. Artinya, pemanfaatan hutan mangrove sebagai tempat mencari makan yang dihitung dengan pendekatan harga pasar diperoleh dari harga makanan ikan jika dibeli di pasar dikalikan perkiraan jumlah makanan ikan yang dikonsumsi. Sedangkan, willingness to pay berarti harga yang akan dibayarkan oleh pengunjung ketika pengunjung tersebut memperoleh pemahaman mengenai konservasi dan pendidikan, serta keinginan pengunjung untuk membayarkan harga masuk kawasan hutan mangrove yang dimanfaatkan sebagai kawasan wisata. Perhitungan nilai konservasi, nilai edukasi, dan nilai wisata di atas dihitung dengan rata-rata keinginan membayar pengunjung dikalikan dengan perkiraan jumlah pengunjung.

\subsection{Nilai total ekonomi mangrove}

Berdasalkan hasil identifikasi dan perhitungan pemanfaatan hutan mangrove di Pulau Untung Jawa, dugaan nilai total ekonomi (TEV) dari hutan mangrove sebesar $\mathrm{Rp}$. 7.895.726.912. Berikut ini tabel nilai total ekonomi mangrove Pulau Untung Jawa.

Tabel 1. Hasil Perhitungan Nilai Toral Ekonomi Hutan Mangrove

\begin{tabular}{clcc}
\hline No & Jenis Pemanfaatan & Nilai Manfaat Total & Presentase \\
\hline 1 & Manfaat Langsung & Rp. 395.126 .912 & $5 \%$ \\
2 & $\begin{array}{l}\text { Manfaat Tidak } \\
\text { Langsung }\end{array}$ & Rp. 7.500.600.000 & $95 \%$ \\
\hline \multicolumn{2}{l}{ Jumlah } & Rp. 7.895.726.912 & $100 \%$ \\
\hline
\end{tabular}

Berdasarkan hasil tersebut, dapat dilihat bahwa mangrove di Pulau Untung Jawa memiliki nilai yang sangat tinggi. Nilai mangrove yang tinggi ini dapat dijadikan sebagai acuan dasar bagi pemerintah dan masyarakat untuk melakukan konservasi mangrove di Pulau Untung Jawa. Masyarakat dan pemerintah diharapkan dapat tetap menjaga dan melestarikan keberadaan hutan mangrove Pulau Untung Jawa.

pengelolaan mangrove di pulau Untung Jawa berbasis green economy

Konsep Green Economy merupakan salah satu konsep baru dalam menciptakan pembangunan lingkungan yang berkelanjutan melalui upaya-upaya yang berkonsepkan Green demi terwujudnya keseimbangan lingkungan. Salah satu penerapan konsep Green Economy adalah dalam bidang konservasi lingkungan yakni dalam pengelolaan mangrove. Konsep penerapan Green Economy dalam upaya penegelolaan mangrove sesungguhnya memiliki tujuan meningkatkan dan menjaga keanekaragaman hayati agar keberadaan atau kelestariannya tetap terjaga serta pemanfaatannya dapat dilakukan secara berkelanjutan.

Kondisi hutan mangrove di Pulau Untung Jawa cukup baik, hal ini dikarenakan masyarakat sekitar turut serta dalam menjaga keberadaan hutan tersebut. Dalam penelitian ini perhitungan Total Economic Value (TEV) dijadikan sebagai suatu parameter dalam penerapan konsep Green Economy. Konsep Green Economy ini dapat diwujudkan dengan adanya peran pemerintah dan masyarakat dalam melakukan konservasi terhadap hutan mangrove. Langkah-langkah tersebut ditetapkan dalam sebuah kebijakan atau aturan pemerintah, kebijakan atau aturan pemerintah.

1. Adanya larangan penebangan hutan mangrove.

Larangan ini ditujukan untuk mengurangi tingkat degradasi hutan mangrove yang ditetapkan sejak tahun 2008 oleh 
pemerintah sebagai bentuk tindak lanjut dari tindakan penebangan liar. Dalam hal ini pihak yang membawa kayu keluar dari hutan mangrove akan mengalami sanksi tegas. Adanya larangan penebangan hutan mangrove merupakan salah satu cara atau kebijakan pemerintah dalam penerapan aspek Green Economy dimana dalam aspek ini lingkungan digunakan sebagai aspek penyeimbang demi terwujudnya lingkungan mangrove yang berkelanjutan.

2. Penanaman Kembali.

Pemerintah bersama-sama dengan masyarakat membuat kebijakan untuk menanam kembali mangrove di lahan yang kosong. Penanaman kembali ini ditujukan untuk mereboisasi hutan mangrove yang rusak akibat degradasi lingkungan. Selain itu, pemerintah juga menyediakan bibit dengan harga terjangkau berkisar antara Rp. 500 Rp. 2000 bagi para wisatawan asing yang ingin turut serta menanam bibit mangrove. Setelah melakukan penanaman, masyarakat akan turut serta dalam memelihara hutan mangrove tersebut. Keterkaitan upaya penanaman kembali mangrove terhadap konsep Green Economy adalah upaya tersebut merupakan suatu tools dalam tebentuknya konsep Green Economy dengan tujuan untuk menjaga terciptanya keanekaragaman dan keseimbangan hayati.

3. Pembersihan Kawasan

Pemerintah menetapkan kebijakan untuk melakukan kerja bakti bersama masyarakat untuk membersihkan sampahsampah yang menumpuk di sekitar hutan mangrove. Pembersihan ini dilakukan setiap minggu oleh masyarakat secara bergiliran. Upaya yang dilakukan tersebut dalam kaitannya dengan konsep Green Economy adalah bahwa upaya pembersihan lingkungan merupakan suatu upaya pemerintah atau masyarakat yang mengarah pada pembentukan lingkungan berkelanjutan guna menyeimbangkan ekosistem serta terciptanya konsep tersebut.

\section{Kesimpulan} globalisasi menyebabkan terjadinya peningkatan permintaan kebutuhan. Peningkatan tersebut menimbukan tekanan terhadap hutan semakin tinggi, salah satunya adalah hutan mangrove. Hutan mangrove merupakan salah satu hutan paling produktif di dunia dan sangat bermanfaat baik dalam fungsi fisik, ekonomi, maupun ekologi. Penelitian ini dilakukan untuk melihat nilai ekonomi hutan mangrove yang ada di kawasan Pulau Untung Jawa. Berdasarkan hasil penelitian, peneliti menemukan bahwa total nilai ekonomi dari hutan mangrove di Pulau Untung Jawa adalah sebesar Rp. 7.895.726.912 yang merupakan penjumlahan dari nilai guna (use value) dan nilai non guna (non-use value). Hasil tersebut menjadi salah satu bukti dari implementasi ekonomi hijau dimana total nilai valuasi ekonomi hutan mangrove mampu dijadikan sebagai salah satu penggerak pemerintah dan masyarakat untuk melakukan langkah konservasi hutan.

\section{Ucapan Terima Kasih}

Penelitian ini tidak akan berhasil tanpa adanya bantuan dari beberapa pihak terkait, oleh karena itu penulis ingin mengucapkan terima kasih kepada Dr. Syam Surya Syamsi selaku kepala Surya Center for Community Development (SCCD), Dandy Eko Prasetiyo, M.Si. dan Firman Zulfikar, M.Si. selaku pembimbing dalam penelitian, Victoria Lelu Sabon, Ph.D. selaku Kepala Program Studi Green Economy, serta para stakeholder dan masyarakat Pulau Untung Jawa yang terlibat dalam penelitian ini.

\section{Daftar Pustaka}

Aksornkoae, S. 1993. Ecology and Management of mangroves. IUCN Wetlands Pragramme, Bangkok.

Dharmawan, I.W.S., Siregar, C.A. 2008. Karbon Tanah dan Pendugaan Karbon Tegakan Avicennia marina (Forsk.) Vierh. di Desa Ciasem, Purwakarta. Penelitian Hutan dan Konservasi Alam V 4, 317-328.

Hiariey, L. S. 2009. Identifikasi Nilai Ekonomi Ekosistem Hutan Mangrove Di Desa Tawiri, Ambon. Jurnal Organisasi dan Manajemen 5 (1), 23-34.

Husain, S. A., Badola, R. 2008. Valuing Mangrove Ecosystem Services: Linking Nutrient Retention Function of Manrove Forest to Enhanced Agroecosystem Production. Wetland Ecology Management 16 (6), 441-450.

IUCN. 2007. Environmental and Socio Economic Value of Mangroves in Tsunami Affected Areas.Rapid Mangrove Valuation Study, Panama Village in South Eastern Coast of Sri Lanka. IUCN 
Litbang. 2014. Perkembangan Jumlah Wisatawan Pulau Untung Jawa. Laporan tahunan kelurahan Untung Jawa (2012-2014).

Noor, Y. R., Khazali, M., Suryadiputra, I. N. N. 2006. Panduan Pengenalan Mangrove di Indonesia.

Prasetiyo, D. E. 2013. Struktur Komunitas Mangrove dan Kepiting (Ocypodidae dan Grapsidae), Serta Pendugaan Karbon Tersimpan Pada Komunitas Mangrove di Kabupaten Raja Ampat. Skripsi. Universitas Jenderal Soedirman. Purwokerto.

Qodriana, L., Hamidy, R., Zulkarnaini. 2012. Valuasi Ekonomi Ekosistem Mangrove di Desa Teluk Pambang Kecamatan Bantan Kabupaten Bengkalis Provinsi Riau. Jurnal IImu Lingkungan 6 (2), 93-98.

Tambunan R., Harahap, R. H., Lubis Z. 2005. Pengelolaan Hutan Mangrove di Kabupaten Asahan (Studi Kasus Masyarakat dalam Pengelolaan Hutan Mangrove di Kecamatan Lima Puluh Kabupaten Asahan). Jurnal Studi Pembangunan 1 (1), 55-69.

UNEP. 2014. Membangun Modal Alam: Bagaimana REDD+ dapat Mendukung Ekonomi Hijau.

Wahyuni, Y. 2014. Valuasi Total Ekonomi Hutan Mangrove di Kawasan Delta Mahakam Kabupaten Kutai Kartanegara Kalimantan Timur. Jurnal Penelitian Kehutanan Wallace 3 (1), 1 12. 
